\title{
Increased Risk of Heart Disease and Stroke Among Foreign-Born Females Residing in the United States
}

\author{
Maria Rubia, MD, PhD, Isabel Marcos, MS, Peter Alexander Muennig, MD, MPH
}

Background: Although the number of foreign-born people residing in the United States is at its highest point in 80 years, a mortality analysis of the foreign born has not been conducted since 1989. This article provides an update of mortality rates among the foreign born in the United States and, in particular, examines mortality rates from heart disease among foreign-born females.

Methods: We calculated mortality rates for U.S.-born and foreign-born people for all causesischemic heart disease, stroke, neoplastic disease, hypertensive diseases, diabetes, accidents, infectious disease, and chronic obstructive pulmonary disease-for 1997. Death data were obtained from the 1997 Multiple Cause of Death data file, and population data were obtained from the 1997 Current Population Survey.

Results: While all-cause, age-adjusted mortality rates for foreign-born people are significantly lower than for native-born people, deaths due to ischemic heart disease and stroke are significantly higher among foreign-born females than native-born females (161.63 and 58.24 deaths, respectively, per 100,000 foreign-born females vs 122.01 and 49.39 deaths per 100,000 native-born females).

Conclusions: Foreign-born females appear to be at greater risk of death from ischemic heart disease and stroke than native-born females. Future research efforts are needed to determine which foreign-born groups are most at risk for heart disease and stroke so that targeted prevention efforts can be initiated.

Medical Subject Headings (MeSH): emigration and immigration, mortality, cross-sectional studies (Am J Prev Med 2002;22(1):30-35) (C) 2001 American Journal of Preventive Medicine

\section{Introduction}

$\mathbf{R}$ ecord numbers of entrants in the 1990s have resulted in the largest number of foreign-born people living in the United States in 80 years. ${ }^{1,2}$ In 1997, approximately $10 \%$ of all people residing in the United States were born in another country. ${ }^{3,4}$ The health of foreign-born populations has come to light largely from a patchwork of studies, making the overall picture of the health status of this population unclear. Also complicating our understanding of the health status of the foreign born is the ever-changing demographic composition of this population. ${ }^{1,5,6}$ Between 1980 and 1990, the number of countries donating at least 100,000 foreign-born people to the U.S. population had increased from 27 to 41. Between 1990 and 1999, the number of people born in Mexico, the

From the New School University, Milano Graduate School, New York, New York

Address correspondence and reprint requests to: Peter Alexander Muennig, MD, MPH, Director, Program in Cost-Effectiveness, New School University Milano Graduate School, 72 5th Avenue, 6th Floor, New York, NY 10011. E-mail: muennigp@newschool.edu.
Philippines, China, Cuba, India, and the former Soviet Union residing in the United States increased dramatically. ${ }^{1}$

Death certificates afford the opportunity to better understand and track the health of foreign-born populations, since they are collected annually and contain information on the country of birth of the decedent. Historical mortality data suggest that recent immigrants, who arrive predominantly from less-developed nations, may be in better health than earlier immigrants, who were predominantly Western European in origin. At the turn of the 19th century, immigration legislation that was targeted explicitly at reducing Asian populations in the United States ${ }^{5}$ resulted in a large demographic shift in the racial and ethnic makeup of the foreign-born population; between 1890 and 1960, foreign-born entrants were overwhelmingly white Europeans. ${ }^{5-7}$ In 1960, the first year that country-of-origin data were collected by country of birth, all-cause, ageadjusted mortality rates for white Europeans were comparable to those of native-born whites. ${ }^{8}$

After liberalization of immigration laws in 1965, the demographic mix of the foreign-born population 
changed dramatically, with many more people from Asian, Latin American, Middle Eastern, and African countries entering the United States. ${ }^{7}$ By the1980s, the all-cause, age-adjusted mortality rates for foreign-born people had declined to levels below those of nativeborn people. ${ }^{9,10}$

Recently, Caribbean-born blacks residing in New York were found to have mortality rates for cardiovascular diseases that were similar to native-born whites, despite the relative poverty of Caribbean-born people. ${ }^{11}$ Thus, there is some evidence that at least some of the predictors of poor health status, such as race/ ethnicity, among the native born may not be predictors of poor health status among the foreign born. However, little work has been done to evaluate the health risks, including lifestyle factors and social determinants of health, among immigrant populations to the United States or other industrialized nations. ${ }^{12}$ This process is complicated by the constantly changing demographics of the foreign-born population, both with respect to the geographic origin of immigrants, as well as the race/ ethnicity, income, and education level of people in foreign-born communities.

Although the foreign born are generally thought of as healthier than the native born due to lower rates of chronic disease, ${ }^{12-14}$ the health of foreign-born populations with respect to non-acute infectious disease and accidents is generally reported to be worse.${ }^{15}$ However, these perceptions may be a result of publication bias. Many of the studies conducted on the prevalence of non-acute infectious disease among the foreign born examine refugee populations or focus on a specific disease, such as tuberculosis. ${ }^{16-18}$ Since the 1990 Immigration Act, large numbers of skilled workers have legally immigrated to the United States ${ }^{5}$ and it is possible that such people enjoyed richer, more westernized diets that may place these populations at greater risk of chronic disease.

Given that the demographic composition of the foreign-born population has changed since the last study on the leading causes of death, an update on overall mortality rates and selected causes of death among all foreign-born people residing in the United States is needed.

\section{Methods}

We examined mortality rates for all foreign-born people residing in the continental United States and Hawaii at the time of their death. While the term "immigrant" refers to people who intend to permanently reside in the United States, the term "foreign born" refers to all people residing in the United States regardless of their immigration status. This broader definition allows for the inclusion of documented and undocumented immigrants, temporary workers, and people awaiting formal immigration proceedings.

\section{Data Sources}

We obtained the total number of deaths and cause-specific deaths for coronary heart disease (ICD-9 codes 410-414); hypertensive cardiopathy (402, 404); hypertension (401, 403); diabetes (250); stroke (430-438); malignant neoplasm (140-208); chronic obstructive pulmonary disease (490496); infection (001-066, 071-088, 090-139); and accidental and external causes of death (E800-E999) from the Multiple Cause of Death Public-Use File for 1997 Data (MCDF-1997). ${ }^{19}$ This data set, which is made available from the National Center for Health Statistics on an annual basis, contains all recorded deaths in the United States and its territories and includes information on the country of origin of the decedent, which is obtained from living relatives.

We obtained population data from the March 1997 annual demographic survey of the Current Population Survey (CPS) by the U.S. Bureau of the Census. ${ }^{20}$ This is a statistical sample of approximately 50,000 households in the United States conducted via face-to-face interviews.

\section{Statistical Analysis}

The data were formatted using SPSS 10 for the Macintosh (SPSS Inc., Chicago, IL). Age-specific mortality rates were calculated by dividing the total number of deaths by the population at risk for those deaths. Age-adjusted mortality rates were calculated using the 1990 U.S. population as a standard population.

Although the total number of deaths and cause-specific deaths obtained from the MCDF-1997 do not constitute a statistical sample, the CPS is subject to sampling error. Since the CPS sample is too small to make reliable comparisons of mortality rates among people born in specific countries or regions of the world, it was necessary to group all foreignborn people together in our analysis. While aggregating foreign-born people into a single category reduced the specificity of our analysis, it improved our ability to match the census data with the mortality data. Country codes for nations other than the United States were grouped into a single variable in each data set.

The March 1997 CPS sample weights were used to extrapolate data from each subject to the overall U.S. population. We compared differences in mortality rates among nativeborn and foreign-born populations using the $z$-test. Details on the formulas and methods for determining significant differences between mortality rates appear elsewhere. ${ }^{19}$

\section{Results}

Table 1 lists the basic demographic characteristics of the U.S. population by country of birth. In 1997, approximately 26 million people were foreign born and approximately 243 million were born in the United States. The foreign born were slightly more likely to be male, older, Asian, and Hispanic than the native born. Approximately 35\% of the foreign born were naturalized citizens. Only $0.57 \%$ of the country-of-origin data fields were missing in the MCDF-1997 data file.

Table 2 lists age-specific, all-cause mortality rates by country of birth. The age-adjusted, all-cause mortality 
Table 1. Demographic profile of foreign-born population in United States

\begin{tabular}{|c|c|c|}
\hline Characteristics & $\begin{array}{l}\text { Foreign } \\
\text { born }\end{array}$ & U.S. born \\
\hline Total number & $25,778,000$ & $243,264,000$ \\
\hline$\%$ Female & $50 \%$ & $51 \%$ \\
\hline Median age & 37 & 34 \\
\hline \multicolumn{3}{|l|}{ Race/ethnicity } \\
\hline Black & $8 \%$ & $13 \%$ \\
\hline Asian/Pacific Islander & $24 \%$ & $4 \%$ \\
\hline White, non-Hispanic & $26 \%$ & $73 \%$ \\
\hline Hispanic & $44 \%$ & $11 \%$ \\
\hline \multicolumn{3}{|l|}{ Region of birth ${ }^{a}$} \\
\hline Latin America & $51 \%$ & - \\
\hline Asia & $27 \%$ & - \\
\hline Europe & $17 \%$ & - \\
\hline Other & $5 \%$ & - \\
\hline \multicolumn{3}{|l|}{$\begin{array}{l}\text { Length of residence in } \\
\text { United States (years) }\end{array}$} \\
\hline$<5$ & $21 \%$ & - \\
\hline $5-9$ & $20 \%$ & - \\
\hline $10-14$ & $14 \%$ & - \\
\hline $15-19$ & $15 \%$ & - \\
\hline$>20$ & $30 \%$ & - \\
\hline Naturalized citizens & $35 \%$ & - \\
\hline
\end{tabular}

${ }^{a}$ Numbers may not add to $100 \%$ due to rounding.

rate was lower for both foreign-born males (853 deaths per 100,000 foreign-born males vs 1003 deaths per 100,000 native-born males) and females (681 deaths per 100,000 foreign-born females vs 670 deaths per 100,000 native-born females). Age-specific mortality rates indicate that foreign-born people are at higher risk of mortality overall than native-born people until age 25 , at which point mortality rates decline sharply for foreign-born people, a trend that continues through the $\geq 85$ years category.

Table 3 lists cause-specific, age-adjusted mortality rates. While foreign-born females were at greater risk of death from ischemic heart disease (162 deaths per 100,000 foreign-born females vs 122 deaths per 100,000 native-born females) and cerebrovascular disease (58 deaths per 100,000 foreign-born females vs 49 deaths per 100,000 native-born females) than U.S.-born females, the rates of these conditions among foreignborn males were similar to or significantly lower than those of native-born males.

While the mortality rates due to hypertension and hypertensive heart disease were significantly higher among foreign-born females than native-born females, mortality secondary to diabetes was significantly lower. The mortality rate of chronic obstructive pulmonary disease, which may be a proxy for smoking, was also significantly lower among foreign-born females than among native-born females (22 deaths per 100,000 foreign-born females vs 33 deaths per 100,000 native-born females).

Death rates from neoplastic disease and violence were lower for both foreign-born females and males than respective native-born groups. Finally, death rates for infectious disease were not statistically different between foreign-born and native-born females, but were significantly lower among foreign-born males compared to native-born males.

\section{Discussion}

While all-cause mortality rates are lower for both foreign-born males and females relative to native-born males and females, foreign-born females appear to be at higher risk of heart disease and stroke than nativeborn females overall. Mortality rates for conditions that suggest the presence of risk factors for heart disease and stroke-hypertension and hypertensive heart disease-indicate that at least some of the higher risk of ischemic heart disease is attributable to hypertension. Foreign-born females are at lower risk for chronic obstructive pulmonary disease, a proxy for smoking, and diabetes mellitus, suggesting that the incidence rate of smoking and diabetes mellitus is lower among foreign-born females. Lower mortality rates for neoplastic disease may also indicate lower rates of smoking among foreign-born females, a finding that is consistent with morbidity studies. ${ }^{21-23}$ Given that studies using earlier data demonstrated a downward trend in both heart disease and all-cause mortality among foreign-born females and males alike, our findings are surprising. ${ }^{8-10}$ In addition to high mortality rates from hypertension-associated conditions, it is possible that other factors, such as lower rates of hormone replacement therapy (HRT) among postmenopausal females, also play a role in higher rates of ischemic heart disease among foreign-born females than native-born females (although the benefits of HRT have not been firmly established). ${ }^{24}$ It is also possible that shifts in the demographic mix of immigrants between 1990 and 1997 have contributed to increasing rates of heart disease among foreign-born females. There is some evidence that foreign-born people born in some South Asian countries, one of the fastest-growing donor regions, may be at particularly high risk of coronary artery disease. ${ }^{25}$ For example, Indian and Pakistani females have less favorable lipid profiles than native-born females in general. ${ }^{26}$

Our findings that both foreign-born males and females had lower overall mortality rates relative to native-born people, as well as lower mortality rates for neoplastic disease, chronic obstructive pulmonary disease, and diabetes mellitus, and that foreign-born males had lower rates of infectious disease relative to nativeborn males, were consistent with earlier studies. ${ }^{8,10}$ These results suggest that the higher rates of heart disease and stroke among immigrant females may be distinct from other observed mortality trends among the foreign born. A similar trend among elderly foreign-born females was previously noted in New York City. ${ }^{26}$ 


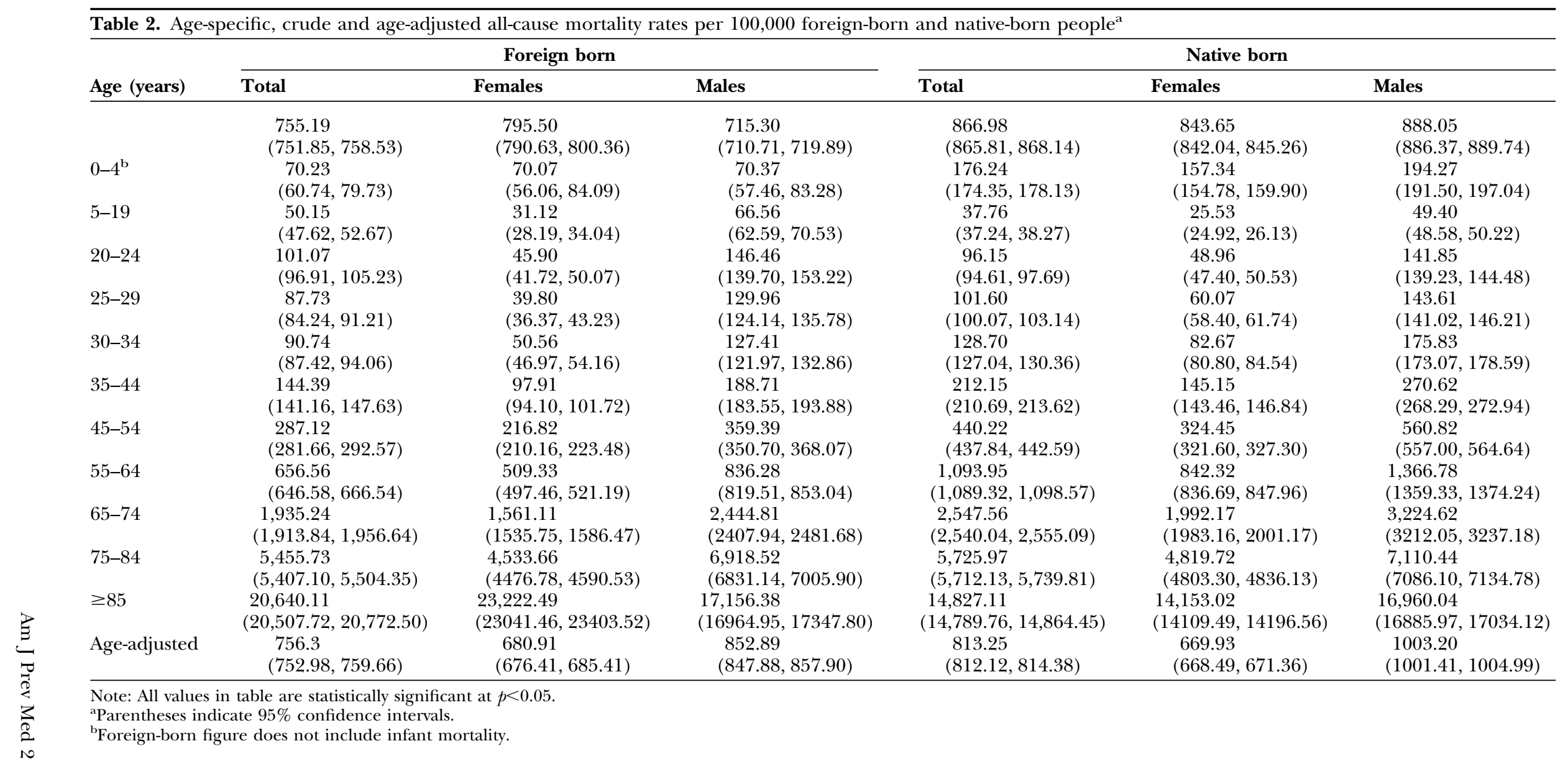


Table 3. Age-adjusted mortality rates for selected conditions by nativity (95\% CI)

\begin{tabular}{|c|c|c|c|c|}
\hline \multirow[b]{2}{*}{ Condition } & \multicolumn{2}{|c|}{ Foreign born } & \multicolumn{2}{|c|}{ Native born } \\
\hline & Females & Males & Females & Males \\
\hline \multirow[t]{2}{*}{ Ischemic heart disease } & $161.63^{*}$ & $198.14 *$ & $122.01 *$ & $209.27 *$ \\
\hline & $(159.43,163.83)$ & $(195.72,200.56)$ & $(121.40,122.63)$ & $(208.45,210.09)$ \\
\hline \multirow[t]{2}{*}{ Hypertensive heart disease } & $10.92 *$ & 10.99 & $9.01 *$ & 10.33 \\
\hline & $(10.35,11.49)$ & $(10.42,11.56)$ & $(8.85,9.18)$ & $(10.14,10.51)$ \\
\hline \multirow{2}{*}{ Hypertension } & $5.13 *$ & 5.11 & $4.43 *$ & 4.78 \\
\hline & $(4.74,5.52)$ & $(4.72,5.50)$ & $(4.31,4.55)$ & $(4.65,4.90)$ \\
\hline \multirow{2}{*}{ Cerebrovascular disease } & $58.24 *$ & 55.24 & $49.39 *$ & 56.27 \\
\hline & $(56.92,59.56)$ & $(53.96,56.52)$ & $(49.00,49.78)$ & $(55.84,56.69)$ \\
\hline \multirow[t]{2}{*}{ Diabetes } & 20.94 & $23.14^{*}$ & 20.62 & $24.03^{*}$ \\
\hline & $(20.14,21.73)$ & $(22.31,23.97)$ & $(20.36,20.87)$ & $(23.75,24.31)$ \\
\hline \multirow[t]{2}{*}{ Neoplasm } & $148.09 *$ & $197.50 *$ & $162.64 *$ & $244.13^{*}$ \\
\hline & $(145.99,150.19)$ & $(195.08,199.91)$ & $(161.93,163.35)$ & $(245.02,243.24)$ \\
\hline \multirow[t]{2}{*}{ COPD } & $21.67 *$ & $32.41 *$ & $32.68 *$ & $51.33^{*}$ \\
\hline & $(20.87,22.48)$ & $(31.43,33.39)$ & $(32.36,32.99)$ & $(50.93,51.74)$ \\
\hline \multirow[t]{2}{*}{ Violence } & $28.73^{*}$ & $76.16^{*}$ & $29.68^{*}$ & $80.04^{*}$ \\
\hline & $(27.80,29.65)$ & $(74.66,77.66)$ & $(29.38,29.98)$ & $(79.54,80.55)$ \\
\hline \multirow{2}{*}{ Infection } & 13.39 & $18.20 *$ & 13.73 & $23.15^{*}$ \\
\hline & $(12.75,14.02)$ & $(17.46,18.93)$ & $(13.52,13.93)$ & $(22.88,23.42)$ \\
\hline
\end{tabular}

*Significant difference between native-born and foreign-born persons of same gender at $p<0.05$.

CI, confidence interval; COPD, chronic obstructive pulmonary disease.

This study was subject to the limitations of the data sources used to calculate mortality rates. We calculated mortality rates using underlying-cause-of-death data reported on 1997 death certificates and the March 1997 CPS. The 1997 mortality data are subject to misclassification bias and are cross-sectional. While it is unlikely that misclassification bias differentially affected the tabulation of mortality rates by nativity, it is possible that systematic bias affected the overall tabulation of cause-specific mortality rates. For example, it is difficult to determine whether reported deaths of ischemic heart disease were the result of other underlying conditions, such as hypertension or diabetes. We minimized misclassification bias by separately examining mortality rates for co-morbid conditions that were likely to be misclassified.

The use of the CPS limited our ability to analyze mortality rates by country of birth. While it is technically preferred to use the mid-point population to calculate mortality rates for a given calendar year, we used the March supplement because it provides a richer source of information. Unless there was a differential rate of mortality between foreign-born people and native-born people or a spike in immigration between March and June 1997, the use of the March supplement rather than the June CPS should not have differentially affected the mortality rates we present here.

Clearly, more work should be done to clarify the relationship between nativity and heart disease among females. Both the underlying risk factors and the populations at risk should be identified so that targeted prevention programs can be designed to address the higher rates of heart disease and stroke among foreign- born females. Once data from the decennial census become available, it should be possible to pinpoint those foreign-born populations most at risk; however, both cross-sectional and longitudinal studies are needed to identify the risk factors for these diseases among the foreign born. One potentially useful source of data is the National Health and Nutrition Examination Survey (NHANES), ${ }^{28}$ which collects laboratory data and detailed nutritional histories using a nationally representative sample of subjects. To date, however, the NHANES has been limited by the inability to separate foreign-born populations by country of birth or region of birth.

Finally, it would be useful to include an analysis of annual changes in mortality rates among the foreign born by region of origin in annual morbidity and mortality rate summaries published by the Centers for Disease Control and Prevention. Presently, mortality data are used to track the progress of the health of the U.S. population by age, gender, income, and race. The time has come to include the newest Americans in the public health agenda so that their health needs can be better understood and better met.

\section{References}

1. Gibson CJ, Lennon E. Historical census statistics on the foreign-born population of the United States: 1850-1990. Washington, DC: U.S. Bureau of the Census, 1999.

2. U.S. Bureau of the Census. Place of birth, citizenship and year of entry: census questionnaire content, CQC-12. Washington, DC: U.S. Bureau of the Census, 1990.

3. New York City Department of City Planning. The newest New Yorkers 1990-1994: an analysis of immigration to NYC in the early 1990s. (Pub. No. DCP 96-19.) New York: New York City Department of City Planning, 1996.

4. U.S. Bureau of the Census. 1990 census of the population: social and 
economic characteristics, New York. Vol. 1 (Section 1). (CP-2-3: Table 168.) Washington, DC: U.S. Department of Commerce, 1993.

5. Fix M, Passel JF. Immigration and immigrants: setting the record straight. Washington, DC: Urban Institute, 1994.

6. Gibson CJ, Lennon E. Historical census statistics on the foreign-born population of the United States: 1850-1990. Washington. DC: U.S. Bureau of the Census, 1999

7. U.S. Bureau of the Census. Profile of the foreign-born population in the United States. Current Population Reports, P23-195. Washington, DC: U.S. Bureau of the Census, 1997.

8. Krueger DE, Moriyama IM. Mortality of the foreign born. Am J Public Health 1967;57:496-503.

9. Kestenbaum B. Mortality by nativity. Demography 1986;23:87.

10. Singh GK, Siahpush M. All-cause and cause-specific mortality of immigrants and native-born in the United States. Am J Public Health 2001;91:392-9.

11. Fang J, Madhavan S, Alderman MH. The association between birthplace and mortality from cardiovascular causes among black and white residents of New York City. N Engl J Med 1996;335:1545-51.

12. Dunn JR, Dyck I. Social determinants of health in Canada's immigrant populations: results from the National Population Health Survey. Soc Sci Med 2000:51:1573-93.

13. Wen SW, Goel V, Williams JI. Utilization of health care services by immigrants and other ethnic/cultural groups in Ontario. Ethn Health 1996;1:99-109.

14. Chen J, Wilkins R, Ng E. Health expectancy by immigrant status, 1986 and 1991. Health Rep 1996;8:29-38.

15. Sun WY, Sangweni B, Butts G, Merlino M. Comparisons of immunization accessibility between non-US born and US-born children in New York City. Public Health 1998;112:405-8.

16. Hayes EB, Talbot SB, Matheson ES, Pressler HM, Hanna AB, McCarthy CA. Health status of pediatric refugees in Portland, ME. Arch Pediatr Adolesc Med 1998;152:564-8.
17. Nelson DR, Hoan Bui, Samet JH. Screening in special populations: a "case study" of recent Vietnamese immigrants. Am J Med 1997;102:435-40.

18. Tornieporth NG, Ptachewich Y, Poltoratskaia N, et al. Tuberculosis among foreign-born persons in New York City, 1992-1994: implications for tuberculosis control. Int J Tuberc Lung Dis 1997;1:528-35.

19. National Vital Statistics System. Multiple cause-of-death public-use file for 1997 data. Available at: www.cdc.gov/nchs/about/major/dvs/mortdata.htm. Accessed July 1, 2000.

20. U.S. Bureau of the Census. Annual demographic survey. Available at: www.bls.census.gov/cps/ads/sdata.htm. Accessed July 1, 2000.

21. Kuo J, Porter K. Health status of Asian Americans: United States, 1992-94. Advance Data Report 298. Hyattsville, MD: National Center for Health Statistics, Centers for Disease Control and Prevention, 1998.

22. Marin G, Pérez-Stable EJ, Marin BV. Cigarette smoking among San Francisco Hispanics: the role of acculturation and gender. Am J Public Health 1989;79:196-8

23. Sundquist J, Winkleby M. Country of birth, acculturation status and abdominal obesity in a national sample of Mexican-American women and men. Int J Epidemiol 2000:29:470-7.

24. Panico S, Galasso R, Celetano E, et al. Large-scale hormone replacement therapy and life expectancy: results from an international comparison among European and North American populations. Am J Public Health 2000;90:1397-402.

25. Enas EA, Yusuf S, Mehta JL. Prevalence of coronary artery disease in Asian Indians. Am J Cardiol 1992;70:945-9.

26. Singh RB. Coronary artery disease risk factors in South Asian and American premenopausal women. Am J Clin Nutr 1999;70:1112-3.

27. Fang J, Madhavan S, Alderman MH. Nativity, race, and mortality: favorable impact of birth outside the United States on mortality in New York City. Hum Biol 1997;69:689-701.

28. National Center for Health Statistics. National Health and Nutrition Examination Survey. Available at: www.cdc.gov/nchs/nhanes.htm. Accessed on March 1, 2001. 